\title{
Crow Process Modeling
}

\section{Topical Report}

November 1, 1995- January 31, 1996

Work Performed Under Contract No.: DE-FC21-93MC30126

\author{
For \\ U.S. Department of Energy \\ Office of Fossil Energy \\ Morgantown Energy Technology Center \\ P.O. Box 880 \\ Morgantown, West Virginia 26507-0880
}

By

Western Research Institute

The University of Wyoming Research Corporation

P.O. Box 3395, University Station

Laramie, Wyoming 82071-3395 


\section{Disclaimer}

This report was prepared as an account of work sponsored by an agency of the United States Government. Neither the United States Government nor any agency thereof, nor any of their employees, makes any warranty, express or implied, or assumes any legal liability or responsibility for the accuracy, completeness, or usefulness of any information, apparatus, product, or process disclosed, or represents that its use would not infringe privately owned rights. Reference herein to any specific commercial product, process, or service by trade name, trademark, manufacturer, or otherwise does not necessarily constitute or imply its endorsement, recommendation, or favoring by the United States Government or any agency thereof. The views and opinions of authors expressed herein do not necessarily state or reflect those of the United States Government or any agency thereof. 


\section{ACKNOWLEDGMENTS}

This report was prepared with the support of the U.S. Department of Energy (DOE ), Morgantown Energy Technology Center, under Cooperative Agreement Number DE-FC21-93MC30126. However, any opinions, findings, conclusions, or recommendations expressed herein are those of the authors and do not necessarily reflect the views of the DOE. 
TABLE OF CONTENTS

LIST OF TABLES AND FIGURES $\ldots \ldots \ldots \ldots \ldots \ldots \ldots \ldots \ldots \ldots$ iv

EXECUTIVE SUMMARY $\ldots \ldots \ldots \ldots \ldots \ldots \ldots \ldots \ldots \ldots \ldots \ldots \ldots \ldots \ldots$

INTRODUCTION $\ldots \ldots \ldots \ldots \ldots \ldots \ldots \ldots \ldots \ldots \ldots \ldots \ldots \ldots \ldots \ldots \ldots$

MODEL FORMULATION $\ldots \ldots \ldots \ldots \ldots \ldots \ldots \ldots \ldots \ldots \ldots \ldots \ldots \ldots \ldots$

Formulation of Equation Set $\ldots \ldots \ldots \ldots \ldots \ldots \ldots \ldots \ldots \ldots \ldots \ldots \ldots \ldots \ldots \ldots$

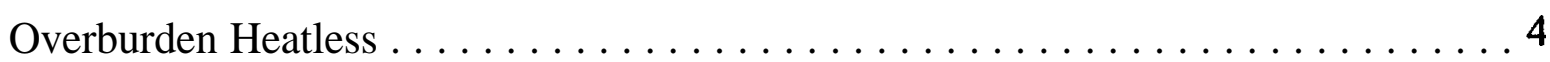

Temperature-DependentRelativePermeability $\ldots \ldots \ldots \ldots \ldots \ldots \ldots \ldots$

Multiple Rock Types $\ldots \ldots \ldots \ldots \ldots \ldots \ldots \ldots \ldots \ldots \ldots \ldots$

No-Flow or Constant-Pressure Boundary Conditions $\ldots \ldots \ldots \ldots \ldots \ldots \ldots .8$

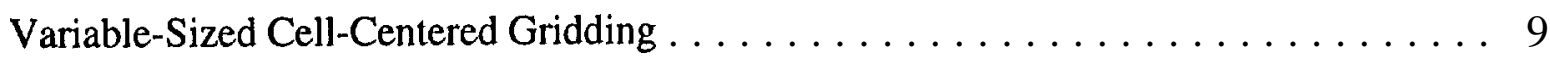

Improvements inWell Terms $\ldots \ldots \ldots \ldots \ldots \ldots \ldots \ldots \ldots \ldots \ldots \ldots$

Improvements in User Interface. . . . . . . . . . . . . . . . . . . . 11

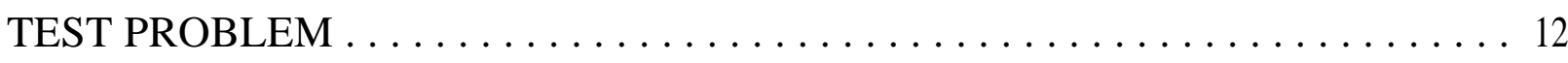

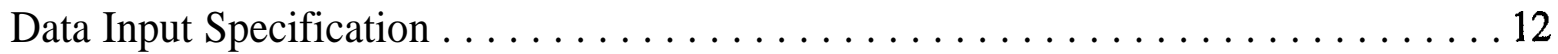

Discussion of Test Problem Results . . . . . . . . . . . . . . . . . 12

SIMULATION OF SUSPENDED ORGANIC EXPERIMENT . . . . . . . . . . 15

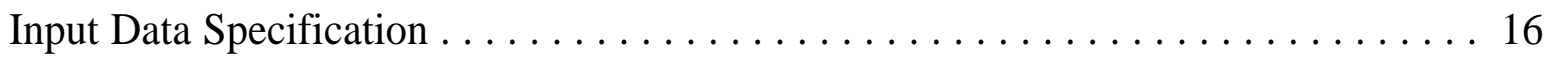

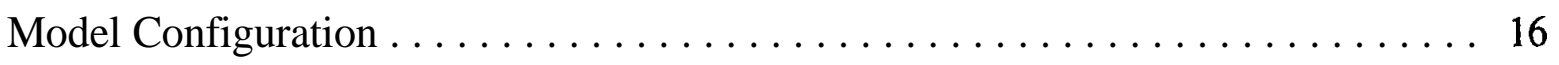

Simulation Results and Discussion $\ldots \ldots \ldots \ldots \ldots \ldots \ldots \ldots \ldots \ldots \ldots \ldots$

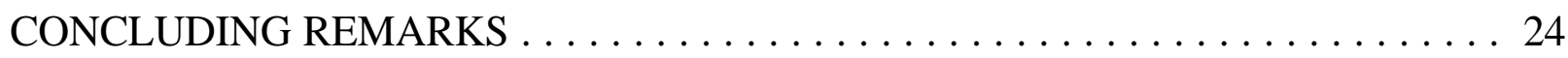

REFERENCES .................................... : 25

NOMENCLATURE . . . . . . . . . . . . . . . . . . . . . . . . . . . 27

APPENDIX I . . . . . . . . . . . . . . . . . . . . . . . . . . . . 29

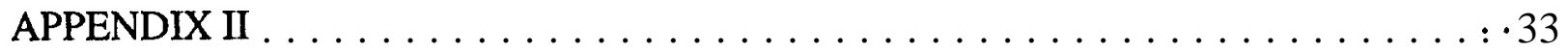

APPENDIX III . . . . . . . . . . . . . . . . . . . . . . . . . . 


\section{LIST OF TABLES AND FIGURES}

Table

Page

1 Test Problem Pressure and Saturation Distributions at Conclusion of Simulation ........................ 14 Al Test Problem Data . . . . . . . . . . . . . . . . . . . . . 27

A2 Input Data for the Suspended Organic Study . . . . . . . . . . . . . . 31

\section{Figure}

\section{Page}

1 Comparison of Oil Recoveries and Water: Oil Ratio for TCROW and

Coats' Formulation . . . . . . . . . . . . . . . . . . . . . . 13

2 Construction of HystereticOil Permeability Curve . . . . . . . . . . . . 19

3 Capillary Relationships U sed in Modeling Lab Experiment . . . . . . . 20

4 Actual and Simulated Productions . . . . . . . . . . . . . . . . . . 23 


\section{EXECUTIVE SUMMARY}

Western Research I nstitute (wRI) has developed a numerical model(TCROW) to describe CROW ${ }^{\mathrm{TM}}$ processing of contaminated aquifers. CROW is a patented technology for the removal of contaminant organics from water-saturated formations by injection of hot water or low-temperature steam. TCROW is based on a fully implicit, thermal, compositional model (TSRS) previously developed by WRI. TCROW'S formulation represents several enhancements and simplifications over TSRS and results in a model specifically tailored to model the CROW process.

In constructing TCROW, the foll owing modifications were made to TSRS:

- The model was reformulated to solve a simplified equation set

- An overburden heat loss algorithm was added

- Ability to specify temperature-dependent relative permeability was added

- Ability tospecify multiple rock properties was added

- Ability to specify either no-flow or constant-pressure boundary conditions was added

- Ability to specify variable-size, point-centered computational grids was added

- Refinements in the calculation of source/sink (well) terms were made

- Improvements in model numerics and user interface were made.

As a test of TCROW'S predictive capabilities, we simulated the recovery of contaminants from a two-dimensional laboratory experiment (J ohnson, et al. 1995). The prediction for overall organic recovery from the experiment was acceptable. However, the model failed to capture correctly the time-dependent production characteristics of the laboratory aquifer. This shortcoming may result, in part, from a lack of precise aquifer data for the experiment. 
An assessment of TCROW'S ability to model field-scale operations can only be made after its use in history matching the production from a contaminated aquifer. At the present time, insufficient data are available to conduct such a study. 


\section{INTRODUCTION}

The Western Research Institute (WRI) has patented a technology (CROW ${ }^{\mathrm{TM}}$ ) for the recovery of oily contaminants from water-saturated formations. The CROW process uses either hot water or low-pressure steam to flush contaminants to the surface by means of production wells. CROW is typically applied to highly permeable aquifers that have been invaded by organics such as coal tars or chemical solvents.

In conceptualizing a model of the CROW process, we draw an analogy between flushing organics from an organic-contaminated aquifer and producing oil from a petroleum reservoir. The organic-contaminated aquifer can be represented as a petroleum reservoir. The injection of water or steam and production of water/organic admixtures can be described by standard reservoir well equations, Finally, the movement of organic and water within the aquifer can be represented bjDarcy flow of the individual phases. Thus, in modeling the CROW process, it is reasonable to assume that a petroleum reservoir simulator would accurately portray the recovery of organics from a contaminated aquifer. Of course, the reservoir simulator would need to incorporate thermal aspects ofDarcy flow to accurately represent recovery during CROW processing.

Using the previously described logic, WRI developed a thermal model (TCROW) to simulate operations when the CROW process is applied to an aquifer. TCROW is actually a revision of TSRS, a model originally developed by WRI to investigate thermal recovery technologies in the laboratory (Vaughn 1986). TSRS was further revised for use in simulating field-scale problems (Mones 1993). For reference, the 1993 report is included as Appendix III.

Devel opment of TCROW resulted from experience gained in simulating CROW operations for actual aquifers. These field-scale CROW simulations have been for design purposes only; so at this time TCROW has not been used to history match field performance.

\section{MODEL FORMULATION}

In devel oping TCROW, many of the preceding model's (TSRS) numerics have been retained. TCROW remains a fully implicit thermal simulator that solves the 
transport of steam, water, organic, and energy by assuming Darcy flow. However, because CROW processing operates at temperatures that obviate chemical reactions, TCROW has been formulated as a noncompositional model. In addition, TCROW does not consider a noncondensible gas component, because CROW is applied to waterorganic aquifers with no mobile gas phase. These simplifications to TCROW's formulation result in faster computation times and, in comparison with TSRS, simpler data input for the user.

In constructing TCROW, the following modifications were made to TSRS:

- The model was reformulated to solve a simplified equation set

- An overburden heat loss algorithm was added

- Ability to specify temperature-dependent relative permeability was added

- Ability to specify multiple rock properties was added

- Ability tospecify either no-flow or constant pressure boundary conditions was added

- Ability to specify variable-size, point-centered computational grids was added

- Refinements in the calculation of source/sink (well) terms were made

- Improvements in model numerics and in user interface were made

These modifications are described bel ow. A description of modifications made to extend TSRS for use as a field-scale simulator is given in Appendix III.

\section{Formulation of Equation Set}

CROW process modeling takes place at temperatures that prevent chemical reactions and in aquifers that do not (initially) contain a mobile gas phase. Given these conditions, it is necessary to solve three equations for the conservation of water, organic, and energy. The alignment of variables to the conservation equations depends on the existence of steam.

In the absence of steam, TCROW is formulated using the following procedure. The model solves primary conservation equations for water phase, oil phase, and energy. In the solution scheme, system pressure $(P)$ is aligned with the water conservation equation; oil saturation (S.) is aligned with the oil conservation equation, 
and aquifer temperature is aligned with the energy conservation equation. Water saturation is given by the constraint:

$$
S_{w}=1-S_{0}
$$

The gas saturation $\left(\mathrm{S}_{\mathrm{g}}\right)$ is set to zero.

In the presence of steam, the formulation is as follows. The water saturation is determined by the water conservation equation, which accounts for both the liquid and gas phase water component. Organic saturation and temperature are calculated as before. Aquifer pressure is determined with the constraint:

$$
P=P w_{\text {sat }}(T)
$$

where $\mathrm{Pw}_{\text {sat }}$ is the saturation steam pressure at aquifer temperature $(T)$. The gas saturation $\left(\mathbf{S}_{\mathbf{g}}\right)$ is calculated with the constraint:

$$
S_{g}=1-S_{w}-S_{o}
$$

The selection between the alternative model formulation schemes is done dynamically within the model, depending on the existence of steam. For each computational grid, a determination is made using the equation:

$$
K e=P / P w_{s a t}(T)
$$

If Ke exceeds or equals the value of 1 , then water vapor pressure is greater than system pressure, and a gas phase exists. The converse is true with Ke less than 1.

The transition to and from the steam phase is a highly dynamic process that occasionally resulted in numerical instability and failure of the model. This tendency for instability has been significantly reduced by incorporating a 200-point representation of the steam table into the model for the determination of water properties. When plotted, this finely gridded table gives the appearance of smoothly 
varying, continuous property functions. This smoothness results in the calculation of continuous derivative functions, even under conditions of phase change. We have found that continuous derivatives are necessary for the convergence of TCROW's numerical solution scheme. The steam table is used to determine values for gas and liquid densities; saturation temperature and pressures; and gas and liquid enthalpies.

\section{Overburden HeatLoss}

Heat loss to the confining overburden and underlying strata is calculated by assuming unsteady-state conduction in a semi-infinite medium. Integration of the heat loss calculation within TCROW follows a method described by Coats et al. (1974) and is summarized here. For brevity, we confine our discussion to the overburden, since heat loss to the underlying strata is treated identically. Heat loss to the overburden at each surface element is described by the heat-transfer equation:

$$
K_{o v} \frac{\partial^{2} T}{\partial z^{2}}=(\rho C p)_{o v} \frac{\partial T}{\partial t}
$$

where $\mathrm{K}_{\mathrm{ov}}$ is thermal conductivity in $\mathrm{Btu} / \mathrm{hr}-\mathrm{ft}-{ }^{\circ} \mathrm{F}, \rho$ is overburden density $\mathrm{lb} / \mathrm{ft}^{3}$, and $z$ is the vertical dimension in feet. The left-hand side of equation 5 accounts for the transport of heat, and the right-hand side represents heat accumulation. In TCROW, this differential heat-transfer equation is solved by an implicit finite difference technique using variable-sized, point-centered spatial grids. Six grids are used in the solution, with grid 1 located at the aquifer surface and grid 6 located at some (presumed) infinite distance into the overburden.

The determination of heat loss at each timestep proceeds in three steps.

1. At the beginning of a current timestep $\left(t_{n+1}\right)$ the temperature distribution within the overburden is known by applying the following temperature and time boundary conditions to equation 5 :

$$
\left.T\right|_{z=0, t=t_{n}}=\text { Tres }
$$




$$
\left.T\right|_{z=\infty, t=t_{n}}=\text { Tinit }
$$

where $t_{n}$ is the previous timestep size in days, Tres is the aquifer temperature of the surface element, and Tinit is the invariant, initial temperature at infinite distance into the overburden.

2. Given the temperature distribution in step 1, a temperature distribution for the current timestep $\left(t_{n+1}\right)$ is determined assuming no increase in aquifer temperature from the previous timestep. This requires solving equation 5 with the following boundary conditions:

$$
\begin{gathered}
\left.T\right|_{z=0, t=t_{n+1}}=\text { Tres }\left.\right|_{t=t_{n}} \\
\left.T\right|_{z=\infty, t=t_{n+1}}=\text { Tinit }
\end{gathered}
$$

3. Incremental, additional temperature change in the overburden corresponding to a temperature change at the reservoir surface element from timet $t_{n}$ to $t_{n+1}(\delta \mathrm{T})$ requires solving equation 5 with the initial and boundary conditions:

$$
\begin{gathered}
\left.T\right|_{z=0, t=t_{n+1}}=1 \\
\left.T\right|_{z>0, t=t_{n+1}}=0
\end{gathered}
$$

The heat loss to the overburden $\left(\mathrm{QL}_{\mathrm{N}+1}\right)$ is then calculated as the loss assuming no temperature increase at the aquifer's surface element $\left(\mathrm{QL}_{0}\right)$ (from step 2) plus an incremental loss due to a temperature change during the current timestep (from step 3) or 


$$
Q L_{N+1}=Q L_{O}+\epsilon \delta T
$$

where

$$
\epsilon=K_{o v} / \Delta z
$$

and $A z$ is the vertical distance between the surface of the aquifer and the first grid point in the overburden.

The calculations in steps 1 and 2 occur outside the model's iterative solution loop. Step 3 occurs within the iteration loop.

\section{Temperature.Dependent Relative Permeability}

Two- and three-phase, temperature-dependent relative permeabilities are accommodated in the model. Water and organic relative permeabilities $\left(\mathrm{k}_{\mathrm{rw}}\right.$ and $\left.\mathrm{k}_{\mathrm{row}}\right)$ are input in tabular form as functions of water saturation $\left(\mathbf{S}_{\mathrm{w}}\right)$ at initial aquifer temperature. These relative permeability data are normalized to:

$$
\begin{gathered}
\mathbf{S}_{w}=\left(S_{w}-S_{\text {wir }}(T)\right) /\left(1-S_{\text {wir }}(T)-S_{\text {orw }}(T)\right) \\
k_{r w}^{\prime}=k_{r w} / k_{\text {rwro }}(T) \\
k_{\text {row }}^{\prime}=k_{\text {row }} / k_{\text {roiw }}(T)
\end{gathered}
$$

The temperature-dependent endpoints of $\mathbf{S}_{\text {wir }}$ (irreducible water saturation), $\mathbf{S}_{\text {orw }}$ (residual organic saturationto water), $\mathrm{k}_{\text {rwro }}$ (relative permeability to water at residual organic), and $\mathbf{k}_{\text {roiw }}$ (relative permeability to organic at irreducible water) are read in separately as functions of temperature. 
Two-phase gas-organic relative permeabilities $\left(\mathrm{k}_{\mathrm{rg}}\right.$ and $\mathrm{k}_{\mathrm{rg}}$ ) are input as functions of liquid saturation, $\mathrm{S}_{\llcorner}\left(\mathrm{S}_{\llcorner}=\mathrm{S}_{\mathrm{wir}}+\mathrm{SO}\right)$. Liquid saturation and gas relative permeability are normalized as:

$$
\begin{gathered}
S_{L}^{\prime}=\left(S_{O} S_{\text {org }}(T)\right) /\left(1-S_{\text {wir }}(T)-S_{\text {org }}(T)\right) \\
k_{\text {rog }}^{\prime}=k_{\text {rog }} / k_{\text {roiw }}(T)
\end{gathered}
$$

The temperature-dependent endpoint saturation $\mathrm{S}_{\text {org }}$ (residual organic saturation to gas) is read in separately as a function of temperature. A temperature dependence on gas relative permeability is not considered.

In constructing the normalized relative permeability versus saturation tables, the normalized entries are set to either 1 or 0 (their endpoint values) when their respective saturations fall outside the temperature-dependent saturation limits. This procedure ensures that the interpolated relative permeabilities will not exceed the endpoint values beyond the limits of their respective endpoint saturations.

Actual relative permeabilities are determined at temperature by:

$$
\begin{gathered}
k_{r w}=k_{r w}^{\prime} \cdot k_{r w o}(T) \\
k_{\text {row }}=k_{\text {row }}^{\prime} \cdot k_{\text {roiw }}(T) \\
k_{\text {rog }}=k^{\prime}{ }_{\text {rog }} \cdot k_{\text {row }}(T)
\end{gathered}
$$

When entering the normalized lookup table to determine $\mathbf{k}_{\text {rog }}$, $S_{\llcorner}$is calculated by:

$$
S_{L}=\left(\mathrm{SW}+{ }^{+} S_{o} S_{\text {wir }}(T) \cdot S_{\text {org }}(T)\right) /\left({ }^{1 ‘} \mathrm{~S} \sim \mathrm{i} \sim\left(\sim-S_{\text {org }}(T)\right)\right.
$$


The preceding method of relative permeability normalization is given by Coats (1976). This method only affects endpoint saturations and corresponding relative permeability, while leaving the internal relative permeabilities unaltered.

For three-phase flow, $\mathrm{k}_{, .}$, the relative permeability to organic is calculated by Stone's II method (1973) in modified form (Coats 1980):

$$
k_{r o}=k_{\text {rocw }}(T)\left[\left(k_{\text {row }} / k_{\text {rocw }}(T)+k_{r w}\right)\left(k_{\text {rog }} / k_{\text {rocw }}(T)+k_{r g}\right)-k_{r w}-k_{r g}\right]
$$

\section{Multiple Rock Types}

Multiple rock types are permitted in the model by the specification of alternative relative permeability and/or capillary pressure relationships. On input, sets of rock property table data are assigned an index. The association between index number (i.e. rock property) and location within the simulated aquifer is done using a directionallybased map. This map associates the rock property to a layer within the aquifer. Thus, the specified rock properties are assumed for the entire layer. The layer may be oriented in either $\mathrm{x}-, \mathrm{y}-$, or $\mathrm{z}$-direction, but once established, must remain constant for the entire simulated aquifer. The layer orientation and index map are specified separately from the individual sets of rock data.

\section{No-Flow or Constant-Pressure Boundary Conditions}

The model can be configured for no-flow or constant-pressure boundary conditions. In the x-direction, the no-flow boundary condition is given by:

$$
d P /\left.d x\right|_{x=0, L}=0
$$

and the constant pressure boundary condition is given by:

$$
\left.\mathrm{p}\right|_{x=0, L} \text {. Pboundary } \text { Pbo,L }
$$

The no-flow condition best describes confined pattern floods, and the constant pressure condition describes performance in unconfined aquifers, such as active aquifers. The boundary conditions are specified individually for the $x-, y-$, and $z$-limits of the simulated aquifer. 


\section{Variable.Sized Cell .Centered Gridding}

Variable-sized, point-centered grids have been shown to exhibit better numerical accuracy than variable-sized cell-centered grids (SeeAppendix III). However, the use of cell-centered grids are often preferable when describing the vertical dimension of a simulated reservoir.

By construction, point-centered grids are arbitrarily distributed based on the desired locations of grid points, Cell boundaries are consequently constructed midway between grid points and are not centered with respect to the computational grids. This inability to center a computational point within a cell boundary results in inaccuracy when describing the vertical dimension of the aquifer where properties must be precisely aligned as a function of depth and thickness.

In comparison, variable-sized, cell-centered grids always have their computational points centered within specified cell boundaries. Thus, aquifer properties may be located exactly as a function of depth, as well as coincide numerically with the computational grid.

The model permits both cell- and point-centered grid constructions to be invoked concurrently when describing a simulated reservoir. The form of the finite-difference operator for the variable-spaced, cell-centered grid in terms of quantity $u$ at cell location $\mathrm{i}$ is given by:

$$
\left.L\left(u_{i}\right)=\frac{1}{\Delta \mathrm{x}_{i}} \mid K_{+}\left(\frac{u_{i+1}-u_{i}}{\Delta x_{+}}\right)+K_{-}\left(\frac{u_{i-1}-u_{i}}{\Delta x_{-}}\right)\right]
$$

where $A \mathrm{x}_{+}=.5\left(\Delta \mathrm{x}_{\mathrm{i}}+\Delta \mathrm{x}_{\mathrm{i}+1}\right)$ and $\Delta \mathrm{x}_{-}=.5\left(\Delta \mathrm{x}_{\mathrm{i}-1}+\Delta \mathrm{x}_{\mathrm{i}}\right)$.

$\mathrm{K}_{+}$represents the upwind permeability between cells $i$ and $i+1$, and $K_{-}$is the upwind permeability between cells $\mathrm{i}-1$ and $\mathrm{i}$. 


\section{Improvements in Well Terms}

WRI has developed a method of calculating pressures in point-centered grids with source/sink terms that is numerically more accurate than Peaceman's method (Carlson and Mones 1994). This method has been implemented in TCROW for pointcentered grids. Peaceman's method (Peaceman 1983) for calculating cell pressures is retained for cell-centered grids that contain well terms.

A more accurate method is used to determine the density gradient in flowing production wells (Coats 1980), A flowing-potential, wel lbore gradient is calculated for each layer (1) by:

$$
\gamma w_{l}=\sum_{j=1}^{n p h a s e}\left(\frac{K_{r}}{\mu} P \cdot \gamma\right)_{j}, \sum_{j=1}^{n \text { phase }}\left(\frac{K_{r}}{\mu} P\right)_{j}
$$

where $\mathrm{K}_{\mathrm{r}}$ is the permeability to phase $\mathrm{j}, \boldsymbol{\mu}$ is the viscosity, $\mathrm{P}$ is the phase pressure and $y$ is the phase density. The flowing wellbore pressure for each layer (1) is calculated by:

$$
P w b_{l}=P w b_{l-1}+\left(\gamma w_{l-1} \alpha_{l-1}+\gamma w_{l} \alpha_{l}\right)\left(D_{l}-D_{l-1}\right)
$$

where $D$ is the depth to the center of the grid block, The well bore pressure at layer index $1\left(\mathrm{Pwb}_{1}\right)$ is the limiting (specified) bottomhole well pressure. The $\alpha$ 's account for variable grid spacings. These are calculated by:

$$
\alpha_{l}=0.5 \Delta D /\left(D_{l}-D_{l-1}\right)
$$

and

$$
\alpha_{l-1}=1-\alpha_{l}
$$

where $\Delta \mathrm{D}$ is the vertically measured thickness of the grid block for layer 1 . 


\section{Improvements in User Interface}

Significant effort has gone toward improving the ease of use of the model. These improvements have been in the areas of memory management of the grid system and the input/output processing of grid-specific data.

Previous versions of the model required the user to be intimately familiar with the order of processing data in memory. This order coincided with the construction of the solution matrix. For example, to achieve fastest solution speeds, the model constrained the user to dimension the reservoir (i.e. order the sequence of grids in the $x-, y-$, and $z$-directions) in a manner that resulted in a solution matrix of minimal bandwidth. In effect, the model required the user to input data in a sequence that was efficient for the solution schemes rather than in a sequence that was logical, as suggested by the structure of the reservoir.

An additional difficulty with the model was that it required the user tespecify the bandwidth of the solution matrix. Once specified, it was necessary to recompile the model when the number of grids or dimension of the model changed.

In TCROW, logic has been added so that the model automatically processes the data in memory for fastest solution speeds. This feature is transparent to the user and allows the aquifer to be sized in any order desired. Furthermore, it is no longer necessary to calculate the bandwidth of the solution matrix nor recompile the model when the number of grids or spatial dimensions of the aquifer are changed. The model does not virtually map memory, so the user is limited to a maximum number of grids in each direction, which are specified at compilation time.

Flexible input and output capabilities have been added to the model. The enhanced memory processing promotes the logical input of aquifer data because the ordering of the model often coincides with the order of data input, Additional logic has been added to permit the input and output of data in any direction that is convenient. On input, before listing each class of grid-dependent data (e.g. porosity or saturation), the user specifies the directional order by which data is to be read in. On output, the user specifies the across, down, and layer directions by which data will be printed. The user also specifies the output formatting (floating-point or exponential) and desired conversion factor. 


\section{TEST PROBLEM}

\section{Data Input-Specification}

As an evaluation of model performance, we compared results from TCROW and a three-dimensional steamflood model described by Coats (1976) on a test problem. A statement of the test problem was included with Coats' description of his numerical model formulation. Briefly, the test problem is the steamflood of a two-dimensional, vertical cross-section of a reservoir. The reservoir is $164 \mathrm{ft}$ long by $115 \mathrm{ft}$ wide by 63 $\mathrm{ft}$ thick. The reservoir simulation employs four cell-centered grids for length (horizontal direction) and three grids for thickness (vertical direction). The steamflood is accomplished by injection at constant rate into the bottom layer. The reservoir is subject to heat loss in the vertical direction. Table AI (Appendix I) lists the model data used in simulating the test problem.

F or the calculation of heat loss, no specific information was provided for the thickness of the overburden and underlying strata. Therefore, we estimated an overburden thickness of $150 \mathrm{ft}$ by using the specified initial reservoir pressure and assuming a water-density gradient to the surface. We assumed the thickness of the underlying strata to be the same as the overburden.

Because the model problem assumes no oil-water capillary pressure, TCROW established the initial pressure distribution based on the oil gradient (which is the major phase present). This method of calculating initial pressure distribution is consistent with Coats' model formulation that uses oil-phase pressure as the basis for reservoir pressure. Similarly, TCROW was modified to calculate production rate by using oil-phase pressure rather than individual phase pressure, This method of calculation is unusual in implicit formulations but may have been necessary to promote stability in Coats' semi-implicit formulation. Calculation of production rate by individual phase pressure would result in earlier steam breakthrough and a reduced volumetric sweep efficiency compared to the predictions presented here.

\section{Discussion of Test Problem Results}

Simulation results from Coats'steamflood model and TCROW are compared in Figure 1 and Table 1. Coats' formulation predicted steam breakthrough in 1210 days and an oil recovery of $66.4 \%$ after 1800 days. In comparison, TCROW predicted steam breakthrough in 1256 days with an oil recovery $61 \%$ after 1800 days and $64.5 \%$ after 1900 days of injection. 


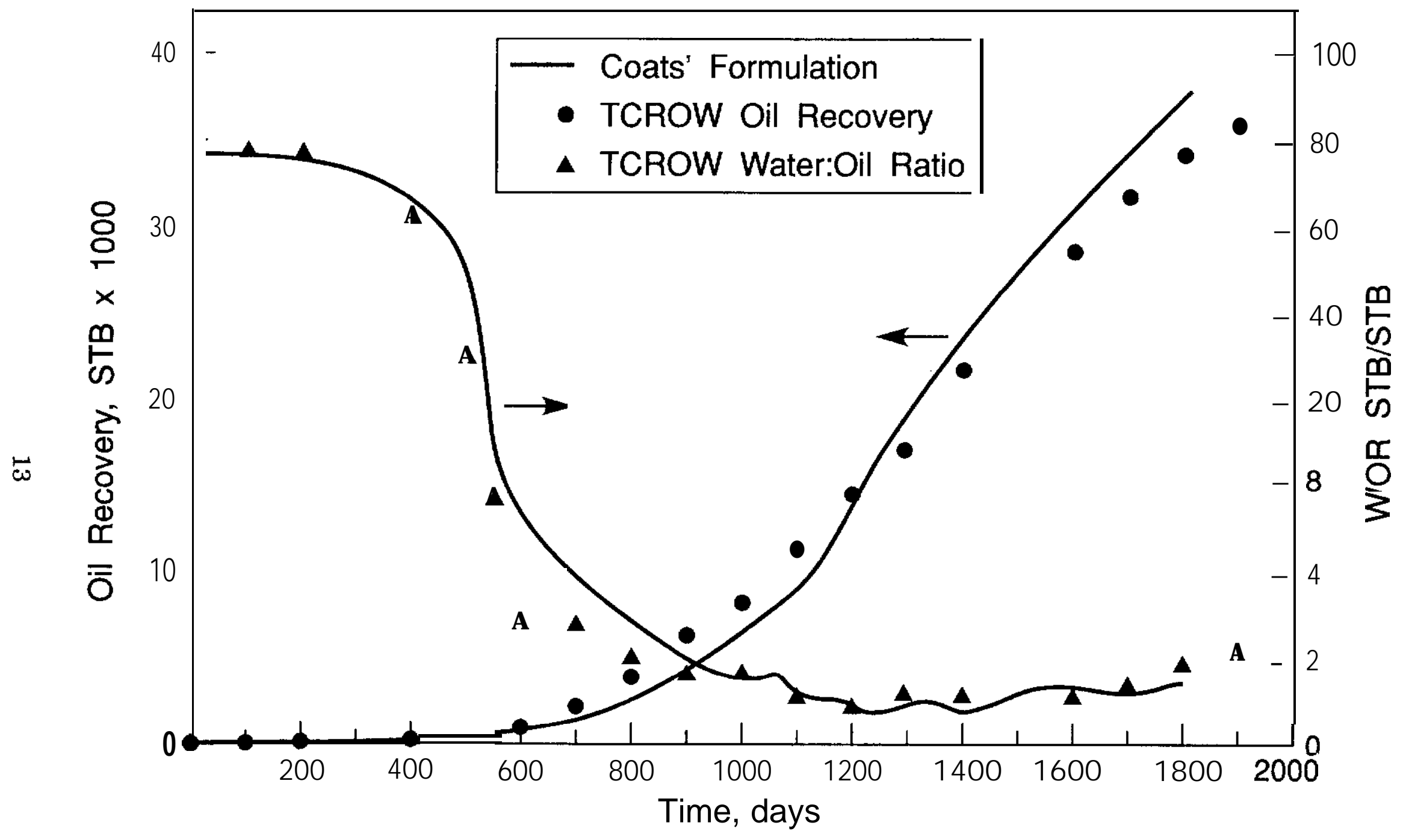

Figure 1. Comparisons of Oil Recoveries and Water: Oil Ratio for TCROW and Coats' Formulation 
Table 1. Test Problem Pressure and Saturation Distributions at Conclusion of Simulation

Coats at 1800 Days

$\begin{array}{llll}\mathrm{x} / \mathrm{y} & 1 & 2 & 3\end{array}$

$\begin{array}{lllll}1 & 64.5 & 63.3 & 62.0 & {[61.0]}\end{array}$

$\begin{array}{lllll}2 & 64.9 & 63.6 & 62.3 & {[61.2]}\end{array}$

$\begin{array}{lllll}3 & (69.6) & 68.5 & 67.4 & {[66.4]}\end{array}$
TCROW at_1900_Days.

$\begin{array}{lllll}1 & 2 & 3 & 4 & x / y\end{array}$

Oil.Phase Pressure

Oil Saturation

63.8

64.3

62.7

$61.5 \quad[60.5] \quad 1$

$\left.\begin{array}{lllll}(68.8) & 67.9 & 66.7 & {[65.8}\end{array}\right]$

\begin{tabular}{llllllllll}
\multicolumn{8}{c}{ Oil Saturation } \\
\multicolumn{10}{c}{} \\
1 & .0904 & .0905 & .0907 & {$[.0911]$} & .0906 & .0906 & $.0907[.0908]$ & 1 \\
2 & .1001 & .1091 & .1195 & {$[.1196]$} & .0979 & .1099 & $.1254[.1299]$ & 2 \\
3 & $1.3879)$ & .5530 & .6637 & {$[.6770]$} & $1.3941)$ & .5770 & $.7104[.7510]$ & 3
\end{tabular}

Water-Saturation

$\begin{array}{llllllllll}1 & .2002 & .2002 & .2003 & {[.2004]} & .2002 & .2002 & .2003 & {[.2003]} & 1 \\ 2 & .2004 & .2005 & .2008 & {[.2012]} & .2004 & .2005 & .2009 & {[.2011]} & 2 \\ 3 & 1.2377) & .2387 & .2609 & {[.2660]} & 1.2462) & .2438 & .2896 & {[.2690]} & 3\end{array}$

Steam Saturation

$\begin{array}{llllllllll}1 & .7094 & .7093 & .7090 & {[.7085]} & .7092 & .7091 & .7090 & {[.7089]} & 1 \\ 2 & .6995 & .6904 & .6797 & {[.6792]} & .7017 & .6896 & .6738 & {[.6689]} & 2 \\ 3 & (.3745) & .2083 & .0759 & {[.0570]} & 1.3596) & .1792 & .0000 & {[.0000]} & 3\end{array}$

( ) = injection layer

[ ] = production layer 
The difference in recovery between the two models was caused by the better steam sweep efficiency evident with Coats' model. Or conversely, TCROW exhibited a greater tendency for steam override (Table 1). This override contributes to the divergence between the cumulative oil production curves following steam breakthrough (Figure 1).

Several numerical parameters were adjusted in an attempt to improve agreement between the two models. These adjustments included reducing the timestep size, changing the upwind weighting factors for the calculation of interblockflow fluid properties, and repositioning the grid locations for the heat loss calculation. None of these changes resulted in an improved overall agreement for predicted oil recovery.

Another cause for the discrepancy between the predictions of the two models may be the degree of implicitness employed in their respective formulations. In Coats' formulation, densities, viscosities, relative permeabilities, and enthalpies in the interlock flow terms are treated explicitly, as are temperatures in the heat conduction

terms. In comparison, TCROW used implicit dating for temperature-dependent terms as well as all quantities associated with the interlock flow terms. It is reasonable to assume that the different method of dating would result in a degree of variability in phase nobilities between the models. In any case, the correspondence between predictions is reasonable, which suggests that TCROW is operating satisfactorily.

\section{SIMULATION OF SUSPENDED ORGANIC EXPERIMENT}

We performed a simulation study of the $140^{\circ} \mathrm{F}$ injection temperature, suspendedorganic experiment with the goal of matching organic recoveries. This twodimensional experiment was configured initially with an organic zone located between two water zones. We restricted our analysis to this test because of the availability of relative permeability data. The entire physical simulation study is presented in J ohnson et al. (1995).

After 1.6 days of injection, 94 grams (or $10 \mathrm{wt} \%$ of the original organic in place) was produced from the lab-scale aquifer. Following injection, a core analysis indicated a distribution of organic saturations that were arrayed along a line of symmetry 
extending longitudinally between the injection and production intervals. The highest valued organic saturations generally occurred along the centerline and dissipated in the vertical direction, This distribution of saturations suggested that the injected water may have bypassed the organic zone. Another possibility for the distribution could be a migration of organic and water phases caused by an imbalance in capillary forces between the water and organic zones, This migration presumably would have occurred prior to water injection. Both of these possibilities would account for the relatively low organic recovery of this test.

\section{Input Data Specification}

The simulations conducted for this study used normalized, Corey-type (1954) functional relationships to calculate the relative permeability for both water and organic phases. These relationships require the use of residual saturations and corresponding phase permeabilities. Those determinations were made by WRI with an organic of similar properties and with the identical sand used in the experiment. Temperature-dependant relationships for organic viscosity and density were based on data available from a representative organic. The absolute permeability for thitwodimensional aquifer was estimated by matching pressure drop measurements obtained during a single-phase water injection test. Water/organic capillary pressure relationships for the organic zone were developed using data reported for a TCE/water/unconsolidated-sandstone system (Guarnaccia et al. 1992). The data of Guarnaccia et al. were for a secondary-drainage/imbibition system that was operated to residual saturations and therefore did not measure the primary drainage capillary pressure. Consequently for the water zone, we estimated a primary drainage capillary pressure relationship using a first-order approximation. The data used in the study are summarize in Table A2 (Appendix II).

\section{Model Configuration}

Because of the layered water/organic/water saturation distribution in the experiment, descriptions of relative permeability and capillary pressure hysteresis were incorporated into the model, The numerical description of hysteresis allowed the model to mechanistically account for the imbibition of water into the organic zone and the resulting migration of organic into the confining water zones. We postulated that this mechanism caused dispersion of the organic phase during static conditions (no 
injection) and, thus, was partially responsible for the low organic recoveries. A further benefit of implementing relative permeability hysteresis was the calculation of permeability to organic based on intermediate, maximum saturations, This method accounted for the fact that the initial oil phase saturation in the experiment did not correspond to its value at the irreducible water saturation $\left(\mathbf{S}_{\mathrm{wir}}\right)$. A generalized description of hysteresis is found in Aziz and Settari (1990). The method of Land (1962) was used to calculate the organic-phase permeability using hysteresis. Killough's method (1976) was used to determine capillary pressure hysteresis.

In addition to its use in analyzing laboratory results, the inclusion of hysteresis physics may provide more accurate predictions when modeling field-scale problems. Often, migration of contaminants into the aquifer is due to capillary or capillary/gravity forces. Under these conditions, a description of hysteresis could be employed to account for phase movement and, thus, provide better estimates of saturation distribution. Furthermore, since the initial saturation of contaminants rarely corresponds to that at $\mathbf{S}_{\text {wir }}$, permeability to organic is most accurately calculated using hysteresis.

The water and organic relative permeability relationships used in the study are given by:

$$
\begin{aligned}
& k_{r w}=k_{\text {rwo }}(T)\left[\frac{S_{w}}{1-\mathrm{S}_{\text {or }} \mathrm{e}(\mathrm{T}) S_{\text {wir }}(T)}\right]^{\mathrm{n}_{w}} \\
& k_{\text {row }}=k_{\text {roiw }}(T)\left[\frac{\left.1-S_{o r w}(T) S_{w}^{-} S_{w}\right)^{n_{\text {ow }}}(T)^{-} S_{\text {wir }}(T)}{1-S_{\text {or }}}\right.
\end{aligned}
$$

The exponents (or shape factors) $\mathrm{n}_{\mathrm{w}}$ and $\mathrm{n}_{\text {ow }}$ were each initialized to a value of 3 , a value we thought reasonable for unconsolidated sand. The study assumed no temperature dependence on relative permeability.

Individual relative permeability relationships described the organic and water zones. The calculation of the permeability to organic in the organic zone required the 
use of an imbibition curve (developed after a complete drainage displacement had taken place) and a primary drainage curve. The imbibition curve was calculated with equation 22 using residual values measured byVRI for $S_{\text {wir }}, S_{\text {orw }}$ and $k_{\text {poiw }}$. The primary drainage curve was calculated with equation 22 using the measured $\mathbf{S}_{\text {wir }}$ (and corresponding $\mathrm{k}_{\text {roiw }}$ ) and assuming a value of $\mathrm{O}$ for $\mathrm{S}_{\text {orw. }}$. The hysteresis relative permeability curve was then constructed using the drainage and imbibition curves together with the point of maximum water saturation (for example, see Figure 2). Numerically, the model calculated the hysteretic permeability by using the trapped organic saturation and the point of maximum organic saturation for each grid point and at every time step.

F or the water zones, the calculation of permeability to organic followed the primary drainage curve unless the water saturation increased. This point of reversal became the maximum water saturation for the grid point. Subsequently, under conditions of increased water saturation, the permeability to organic was calculated analogously to that in the organic zone.

Similarly, two relationships were needed to describe the capillary pressures in the organic and water zones. Bounding curves were input using available capillary pressure data for imbibition and secondary drainage. These bounding curves were used to devel op the hysteretic capillary pressure relationship for the water phase in the organic zone. A graphical representation for the construction of a hysteretic capillary pressure curve is shown in Figure 3. Determination of capillary pressure in the water zone required the use of a primary drainage curve. As with the permeability to organic, the capillary pressure in the water zone traced the primary drainage curve unless the water saturation increased. After that point, capillary pressures were determined analogously to that in the organic zone.

No data were available for the primary drainage capillary pressures. Therefore, we estimated this curve by assuming a straight-line relationship between the value of capillary pressure at $S_{w}$ of 1 (entry capillary pressure) and the point of attachment to the secondary drainage curve $\left(S_{w}=0.76\right.$ fraction of pore volume). In this study, the value for entry capillary pressure was used as an adjustable parameter to match organic recovery. 


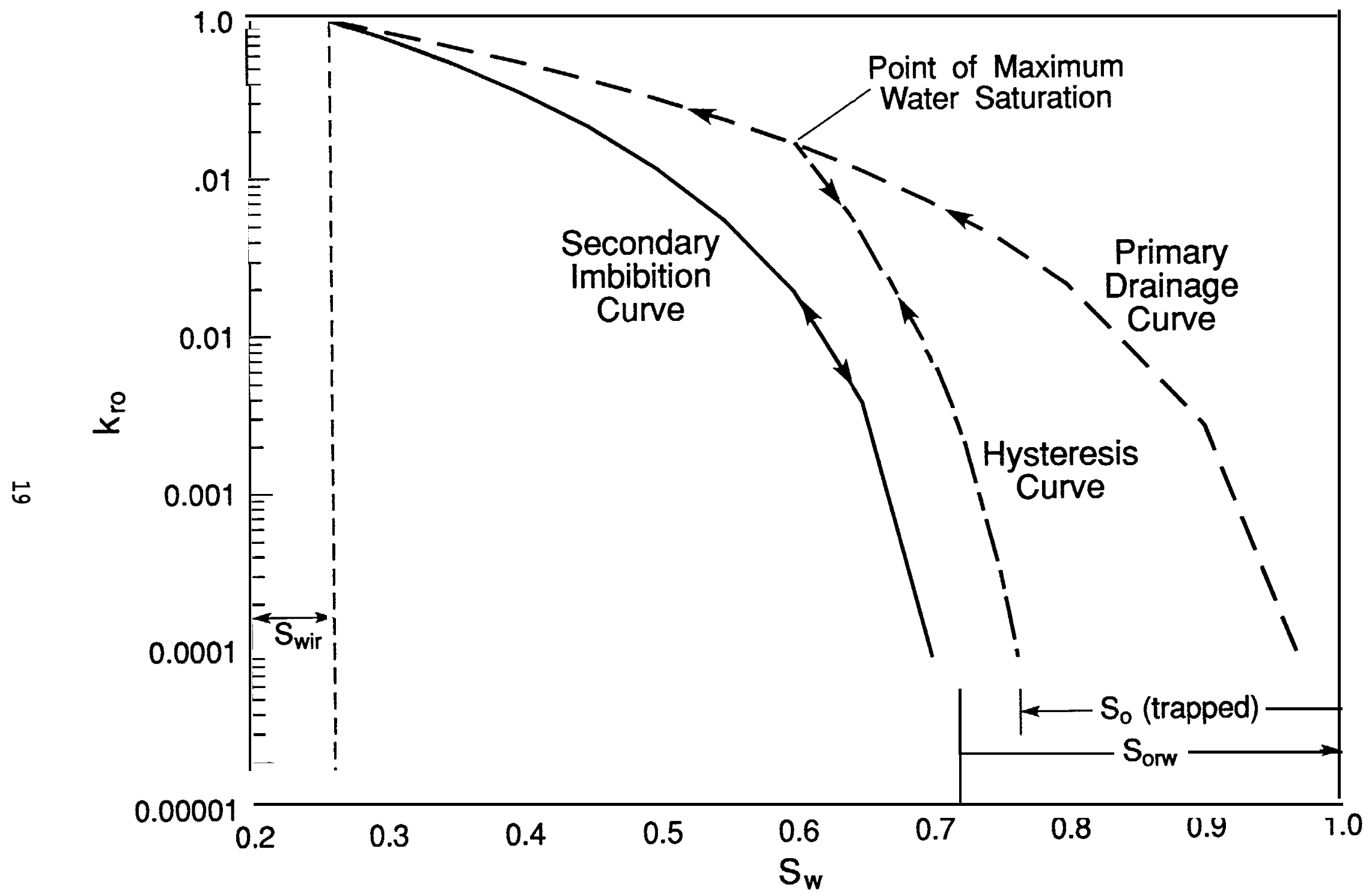

Figure 2. Construction of Hysteretic Oil Permeability Curve 


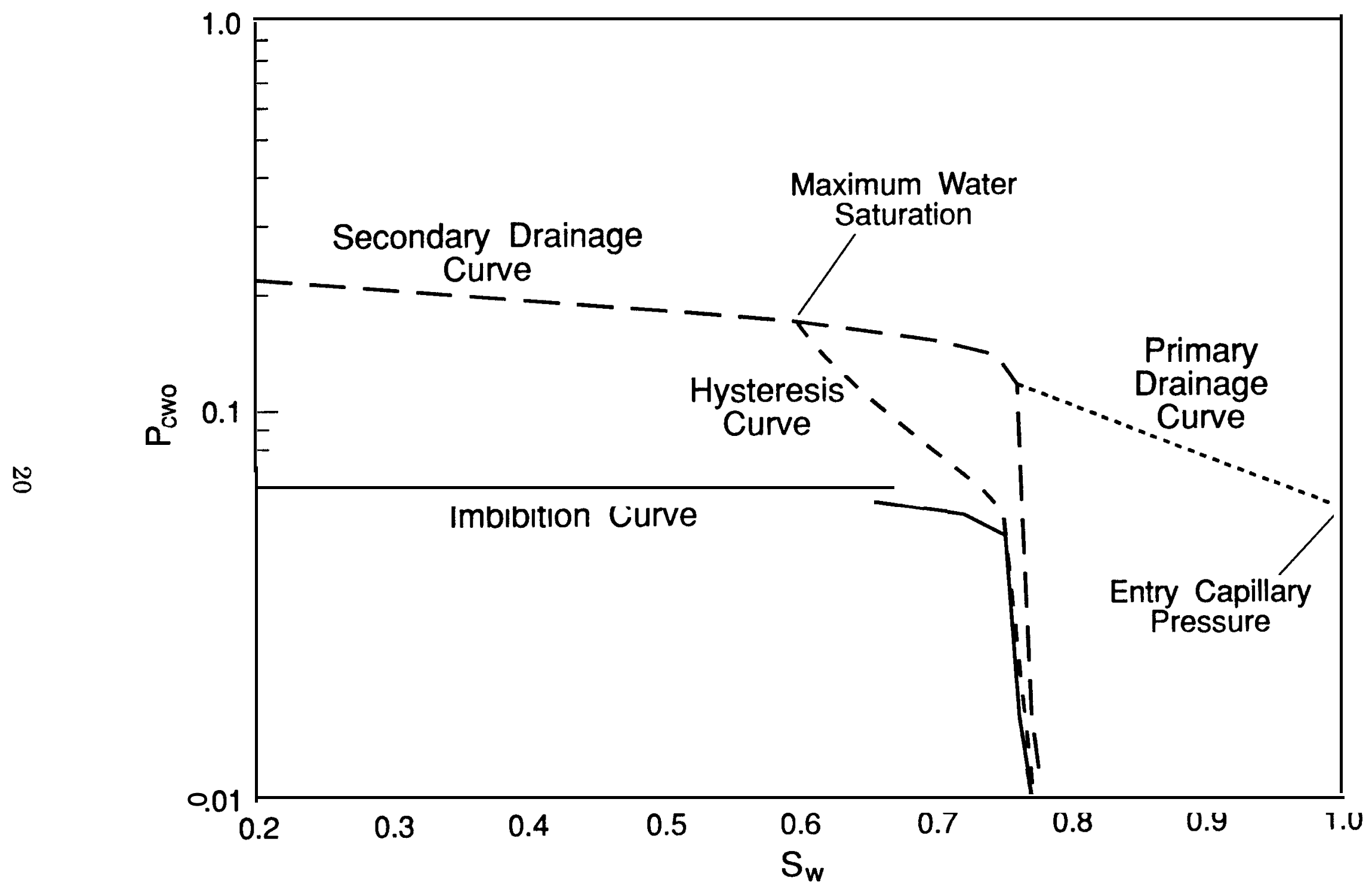

Figure 3. Capillary Relationships Used in Modeling Lab Experiment 


\section{S'mulation Results and Discussion}

The experiment was modeled using 20-vertical (gravity direction) by 10 horizontal grids. Before commencing water injection, thesimulation permitted an initial period for redistribution of the phases. Consistent with the operation of the experiment, we permitted a period of $2.5 \mathrm{hrs}$ before establishing water injection into the aquifer. Thereafter, a constant $51 \mathrm{lgm} / \mathrm{hr}$ of water was injected at a temperature of $140^{\circ} \mathrm{F}\left(60^{\circ} \mathrm{C}\right)$. Heat loss to the surroundings was neglected.

As mentioned earlier, the entry capillary pressure was adjusted to match final organic recovery. This pressure, along with the point of attachment to the secondary drainage curve, defined the capillary pressure/saturation relationship for primary drainage. We achieved a close match for final organic recovery with an entry pressure of $0.0537 \mathrm{psi}$. This value for entry capillary pressure is reasonable in that its magnitude fell between the secondary drainage and imbibition curves. The organic recovery was quite sensitive to entry capillary pressure, with a $10 \%$ variation in pressure resulting in a $5 \mathrm{wt} \%$ variation in organic recovery. This sensitivity is related to the degree of organic migration that occurred before establishing water injection. The greater the disparity in pressure between the water and organic zones the greater the migration of organic from the organic zone.

The entry capillary pressure was the only parameter adjusted when modeling the effects of hysteresis. It would have been possible to adjust other parameters, the most obvious being those associated with the relative permeability, However, given the degree of uncertainty in the data set, it was considered prudent to restrict parameter adjustment to the quantity about which the least was known (i.e. capillary pressure).

In addition to hysteresis/capillary-pressure physics, we predicted recoveries under conditions of bypassing of injected water. These predictions assumed no capillary pressure, no hysteresis effects and used relative permeability values measured by WRI. To achieve the highest degree of bypassing, the simulations used a permeability to organic that was measured at ambient temperature and a permeability to water that was measured at $160^{\circ} \mathrm{F}\left(71^{\circ} \mathrm{C}\right)$. The combination of phase permeabilities associated the lowest permeability to water with the lowest permeability to organic in the organic zone. The primary drainage curve relationship defined the 
permeability to water in the water zone. Thus, this configuration caused a high degree of water injection into the confining water zones (bypassing the organic zone), which resulted in minimal organic production.

The actual organic recovery is compared with two predicted recovery curves in Figure 4. One curve depicts organic recovery using hysteresis physics, and the other gives recovery of organic with bypassing. The simulation employing hysteresis and capillary pressure between the phases gave closest agreement with actual recoveries, particularly after 0.9 days of operations. This result is not totally unexpected, given the fact that the entry capillary pressure was adjusted to match the final organic recovery of the experiment. However, there is a discrepancy between the shapes of the actual and hysteresis-predicted recovery curves at late times, in that the actual recovery curve appears to turn over (flatten out) more quickly than the predicted recovery curve.

Both predictions for early-time production correspond poorly to actual recoveries, The experimental results indicate that an organic bank was formed, whereas the model predicted none. This result suggests an inconsistency in the initial distribution of organic saturation, incorrect relative permeability relationships, or a problem with the model formulation. An area for further investigation might be the relationship between the water and organic relative permeabilities. The fractional flow relationships indicate that an organic bank could be formed if the permeability to organic were increased or, conversely, the permeability to water were decreased. 


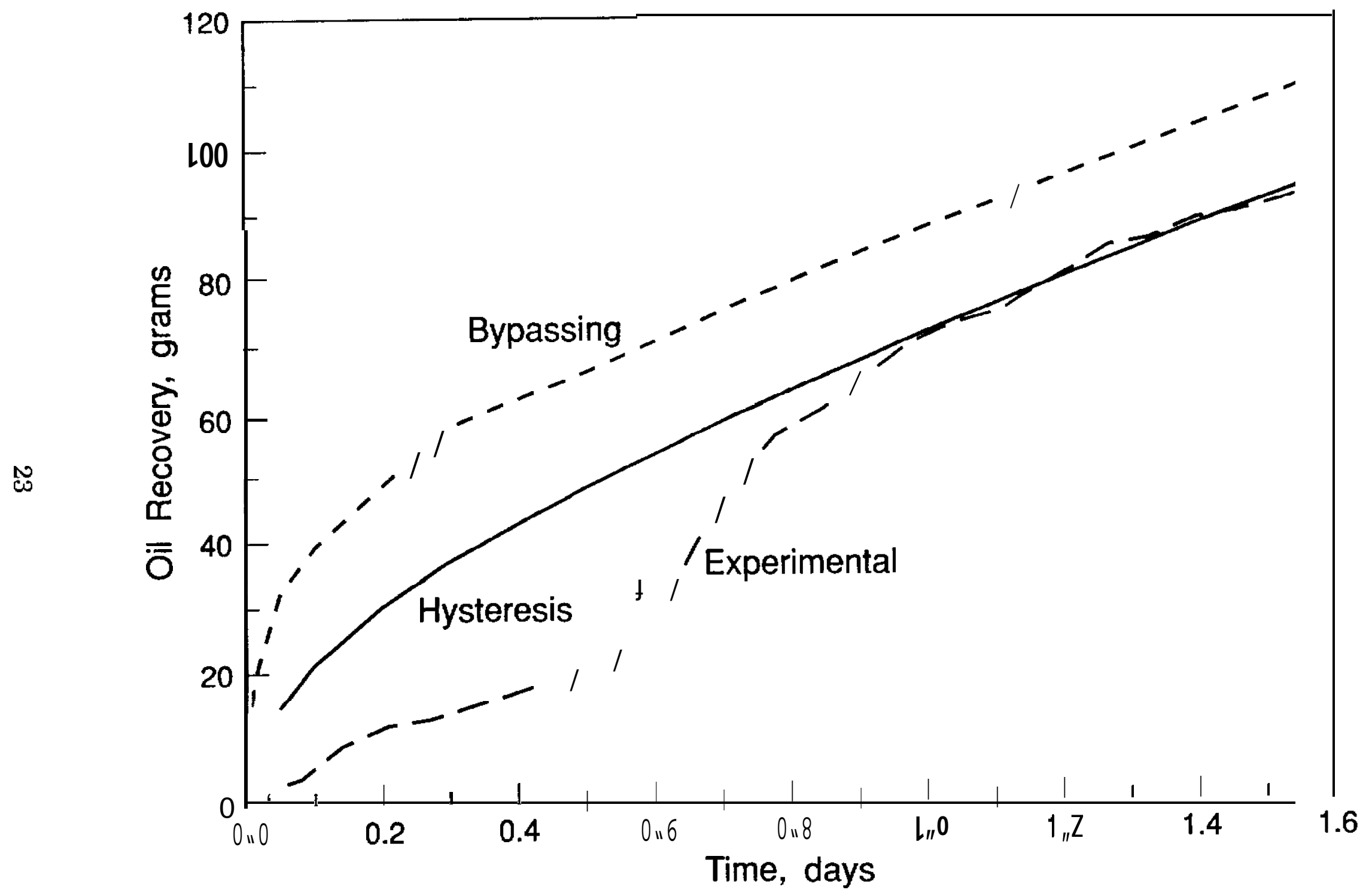

Figure 4. Actual and Simulated Productions 


\section{CONCLUDING REMARKS}

A model has been developed (TCROW) to predict operations when applying the CROW process to organic-contaminated aquifers. TCROW is a fully implicit thermal simulator that embodies simplifications to reduce the solution times when simulating field-scale problems.

At this time, TCROW has not been used to match actual field-scale performance. Thus, it is difficult to ascertain whether the model is formulated correctly to describe all aspects of CROW processing.

TCROW has been marginally successful in describing the CROW process in a laboratory setting. It is reasonable to assume, however, that the discrepancies observed in predicted recovery are at least partially caused by an incomplete data set for the experiments.

The use of capillary pressure and relative permeability hysteresis was a significant aid in analyzing the experimental results. Hysteresis physics are potentially a key factor for correctly simulating field-scale simulations. 


\section{REFERENCES}

Aziz, K., and A. Settari, 1990, Petroleum Reservoir Simulation. Elsevier Applied Science, New York, 395-401.

Carlson, F.M. and C.G. Mones, 1994, "Resolution of the Inconsistency Between Peaceman's Well-block Pressure and the Average Pressure of the Well Block,"CIM J une 1994, Paper 94-25.

Coats, K,H., 1976, "Simulation of Steamflooding with Distillation and Solution Gas," SPEJ , Oct. 1976,235-247.

Coats, K. H., W.D. George, Chu Chieh, and B.E. Marcum, 1974, "Three-Dimensional Simulation of Steamflooding," SPEJ , Dec. 1974, Trans., AIME, 257,573-592.

Coats, K. H., 1980, “In-Situ Combustion Model,"SPEJ , Dec. 1980,533-553.

Corey, A.T., 1954, Producer's Monthly, 38, November, 19.

Guarnaccia, J . F., P.T. Imhoff, B.C. Missildine, M. Dostrom, M.A. Celia, J.H. Dane, P.R. Jaffe, and G.F. Pinder, 1992, Multiphase Chemical Transport in Porous Media, EPA Environmental Research Brief, EPA/600/5-92/002.

J ohnson, L.A., J r., C.G. Mones, and K.P. Thomas, 1995, "CROW" ${ }^{\mathrm{TM}}$ Process Modeling," Topical Report, Western Research Institute, Laramie, WY,WRI-95-R012.

Killough, J . E., 1976, "Reservoir Simulation with History-Dependent Saturation Functions," SPEJ, Feb. 1976, Trans., AIME, 261,37-48.

Land, C. S., 1968, Calculation of Imbibition Relative Permeability for Two- and ThreePhase Flow from Rock Properties," SPEJ , J une 1968, Trans., AIME, 243, 149156.

Mones, C, G., 1993, Modifications to WRI's Thermal Model: Development Toward a Field-Scale Simulator, Western Research Institute, Laramie, WY,WRI-93-R033. 
Peaceman, D.W., 1983, Interpretation of Well-Block Pressures in Numerical Reservoir Simulation with Nonsquare Grid Blocks and Anisotropic Permeability, SPEJ, J une 1983,531-543.

Stone, H. L., 1973, Estimation of Three-Phase Relative Permeability and Residual Oil Data, J.Cdn. Pet.Tech., 12, No. 4, (Oct./Dee. 1973), 53-61,

Vaughn, P., 1986, A Numerical Model for Thermal Recovery Processes in Tar Sand: Description and Application, DOE/FE/60177-2219, 


\section{NOMENCLATURE}

$\mathrm{Cp} \quad=$ heat capacity, $\mathrm{Btu} / \mathrm{lbm}-{ }^{\circ} \mathrm{F}$

$\mathrm{D} \quad=$ depth to the center of grid block (from datum), $\mathrm{ft}$

$\mathrm{K}=$ absolute or phase permeability, md

Ke $=$ vapor:liquid equilibrium ratio for water

$\mathrm{K}_{\mathrm{ov}}=$ overburden thermal conductivity, Btu/hr-ft- ' $\mathrm{F}$

$\mathrm{k}_{\mathrm{rg}} \quad=$ relative permeability to gas, fraction

$\mathrm{k}_{\mathrm{ro}} \quad=$ oil relative permeability, fraction

$\mathrm{k}_{\text {rocw }}=$ relative permeability to oil at irreducible water saturation, fraction

$\mathrm{k}_{\mathrm{rog}}=$ relative permeability to oil in a gas/oil system at $\mathbf{S}_{\text {wir }}$, fraction

$\mathrm{K}_{\text {rog }}^{\prime}=$ normalized relative permeability

$\mathrm{k}_{\text {roiw }}=$ relative permeability to oil at irreducible water saturation, fraction

$\mathrm{k}_{\text {row }}=$ relative permeability to oil in an oil/water system

$\mathrm{K}_{\text {row }}^{\prime}=$ normalized relative permeability

$\mathbf{k}_{\mathrm{rw}} \quad=$ water relative permeability, fraction

$\mathbf{k}^{\prime}{ }^{\prime} \mathbf{w}=$ normalized relative permeability

$\mathrm{k}_{\text {rwro }}=$ relative permeability to water at residual oil saturation, fraction

$\mathrm{P} \quad=$ reservoir pressure, psia

$\mathrm{PW} \quad=$ pressure of water phase, $\mathrm{psia}$

$\mathrm{Pwb}=$ well bore flowing pressure, $\mathrm{psia}$

$\mathrm{QL} \quad=$ rate of heat loss, Btu/hr- $\mathrm{ft}^{2}$

$\mathrm{S}=$ phase saturation, fraction of pore volume 


$$
\begin{aligned}
& \mathrm{S}_{\mathrm{g}} \quad=\text { gas-phase saturation, fraction } \\
& \mathbf{S}_{\mathrm{L}}=\text { liquid saturation, fraction } \\
& \mathbf{S}_{\mathbf{L}}^{\prime}, \mathbf{S}^{\prime}{ }_{\mathrm{w}}=\text { normalized saturations } \\
& \mathrm{S}_{0} \quad=\text { oil phase } \\
& \mathrm{S}_{\text {org }} \quad=\text { residual oil saturation to gas, fraction } \\
& \mathrm{S}_{\text {orw }}=\text { residual oil saturation to water, fraction } \\
& \mathrm{t} \quad=\text { time, days } \\
& \mathrm{T}=\text { reservoir temperature, } \mathrm{R} \text { or }{ }^{\circ} \mathrm{F} \\
& \mathrm{x}, \mathrm{z}=\text { distance, } \mathrm{ft} \\
& \alpha \quad=\text { grid block depth weighting factor } \\
& \gamma \quad=\text { density of well fluid, } \mathrm{lbm} / \mathrm{ft}^{3} \\
& \boldsymbol{\epsilon} \quad=\text { heat loss constant, Btu/hr- } \mathrm{ft}^{2} \\
& \mu \quad=\text { viscosity, } \mathrm{cP} \\
& \rho \quad=\text { rock density, } \mathrm{lbm} / \mathrm{ft}^{3}
\end{aligned}
$$




\section{APPENDIX I}

\section{Test Problem Data}


Number of grids in $\mathrm{x}-, \mathrm{y}-, \mathrm{z}$-direction:

Water Compressibility, $\mathrm{C}_{\mathrm{w}}$ (vol/vol-psi):

Oil Compressibility, $\mathrm{C}_{\mathrm{o}}$ (vol/vol-psi):

Rock Compressibility, $\mathrm{C}_{\mathrm{r}}$ (vol/vol-psi):

Oil Thermal Expansion, $\mathrm{C}_{\mathrm{T}}$ (vol/vol- $\left.{ }^{\circ} \mathrm{F}\right)$ :

Oil-Specific Heat, $\mathrm{Cp}_{\mathrm{o}}\left(\mathrm{Btu} / \mathrm{lb}-{ }^{\circ} \mathrm{F}\right)$ :

Water Density at $\mathrm{T}_{\mathrm{i}}$ and $\mathrm{P}_{\mathrm{i}}\left(\mathrm{lb}-\mathrm{ft}^{3}\right)$ :

Stock Tank Oil Density, $\mathrm{T}=60^{\circ} \mathrm{F}, \mathrm{P}=14.7\left(\mathrm{lb}-\mathrm{ft}^{3}\right)$ :

Init. Reservoir Pressure, Pi, (psi):

(32.5 ft below top of formation)

Init. Reservoir Temperature, $\mathrm{T}_{\mathrm{i}},\left({ }^{\circ} \mathrm{F}\right)$ :

Oil Formation volume factor (RB/STB):

Reservoir Thermal conductivity, $\mathrm{K}_{\mathrm{R}}$, Btu/ ${ }^{\circ} \mathrm{F}-\mathrm{ft}-\mathrm{D}$ :

Overburden Thermal Conductivity, $\mathrm{K}_{\mathrm{ov}}$, Btu/ ${ }^{\circ} \mathrm{F}-\mathrm{ft}-\mathrm{D}$ :

Reservoir- and Overburden-Specific Heat, $(\rho \mathrm{Cp})$, (Btu/ft ${ }^{3}$-rock)

Porosity, $\phi_{\mathrm{i}}$, (fraction):

Initial Water Saturation, $\mathrm{S}_{\mathrm{wi}}$, (fraction of PV):

Initial Oil Saturation, $\mathrm{S}_{\mathrm{oi}}$, (fraction of PV):

Grid-block dimensions $\Delta \mathrm{x}, \Delta \mathrm{y}, \Delta \mathrm{z}(\mathrm{ft})$ :

(Gravity in y-direction)

Well Information:

Injection Well:

Grid-block completion:

Steam Injection, (w.e. bbl/day)
$3,4,1$

$3.1 \times 10^{-6}$

$5.0 \times 10^{-6}$

$8.0 \times 10^{-6}$

$4.1 \times 10^{-4}$

0.5

62.4

55.0

75.0

90.0

38.4

38.4

35.0

0.38

0.30

0.70

$41,21,115$ $i=3, j=1, k=1$

37.5 
Steam Quality at 200 psia

0.7

Production Well:

Grid-block completion:

Well Production Index, PI:

$i=1-3, j=4, k=1$

900.0

(bbl-cP/psi-md-day)

Production pressure, $\mathbf{P}_{\text {well }}$, (psia):

(based at center of top layer)

Overburden and Underlying Strata Thickness,(ft):

Heat Loss Computational Grid Locations,(ft):

60.0

Viscosity of Oil, Water, Gas (CP):

\begin{tabular}{c}
$\mathrm{T}\left({ }^{\circ} \mathrm{F}\right)$ \\
\hline 75 \\
100 \\
150 \\
200 \\
250 \\
300 \\
350 \\
500
\end{tabular}

$\boldsymbol{\mu}_{\mathbf{0}}$
5780
5780
187
47
17.4
8.5
5.2
2.5

$\mu_{\mathrm{w}}$

$0 . \overline{9} 20$

$\mu_{\mathrm{s}}$

0.0095

.681

.0102

.435

.0115

.305

.0127

.0138

.0149

.0158

.0174

Water-Oil Relative Permeability:

\begin{tabular}{lll}
$\mathbf{S}_{w}$ & \multicolumn{1}{c}{$\mathbf{k}_{\mathrm{rw}}$} & \multicolumn{1}{c}{$\mathrm{k}_{\text {row }}$} \\
0.200 & 0. & 1.0 \\
0.250 & 0.0102 & 0.7690 \\
0.294 & 0.0168 & 0.7241 \\
0.357 & 0.0275 & 0.6206 \\
0.414 & 0.0424 & 0.5040 \\
0.490 & 0.0665 & 0.3714 \\
0.557 & 0.0970 & 0.3029 \\
0.630 & 0.1148 & 0.1555 \\
0.673 & 0.1259 & 0.0956 \\
0.719 & 0.1381 & 0.0576 \\
0.789 & 0.1636 & 0.0000
\end{tabular}


$\begin{array}{lll}1.000 & 1.0000 & 0.0000\end{array}$

Gas-Oil Relative Permeability:

\begin{tabular}{|c|c|c|}
\hline$S_{L}=S_{w i r}+S_{0}$ & $\mathrm{k}_{\mathrm{rog}}$ & $\mathrm{k}_{\mathrm{rg}}$ \\
\hline 0.290 & 0.0000 & 0.1700 \\
\hline .395 & .0294 & .1120 \\
\hline .433 & 0461 & .1022 \\
\hline .515 & .0883 & .0855 \\
\hline .569 & 1172 & .0761 \\
\hline .614 & .1433 & .0654 \\
\hline .663 & 1764 & .0500 \\
\hline .719 & 2170 & .03 \\
\hline .750 & 2255 & .0285 \\
\hline .805 & 2919 & .019 \\
\hline .850 & .3373 & .012 \\
\hline .899 & .5169 & .0026 \\
\hline 1.000 & 1.0000 & .0000 \\
\hline
\end{tabular}

Water-Oil Capillary Pressure, $\mathrm{P}_{\text {two }}(\mathrm{psi}): \quad 0.0$ Gas-Oil Capillary Pressure, $\mathrm{P}_{\text {cgo }}$ (psi):

$\begin{array}{cc}\frac{\mathrm{S}_{\mathrm{L}}}{0.29} & \mathrm{P}_{\text {cgo }} \\ 1.00 & -3.0 \\ & -3.0\end{array}$

Vertical and Horizontal Permeability (red): $\quad 4000.0$ 


\section{APPENDIX II}

Input Data for the Suspended Organic Study 
Table A2. Input Data for the Suspended Organic Study

I. Organic Zone

Organic saturation, frac. of P.V.

0.40

Water saturation, frac. of P.V.

0.60

Top of organic zone, $\mathrm{ft}$

0.90

Zone thickness, $\mathrm{ft}$

0.40

Top of injection interval, $\mathrm{ft}$

0.60

Interval thickness, $\mathrm{ft}$

0.80

Top of production interval, $\mathrm{ft}$

0.80

Interval thickness, $\mathrm{ft}$

0.80

$\mathrm{C}_{\mathrm{T}}, \mathrm{vol} / \mathrm{vol}-{ }^{\circ} \mathrm{F}$

2.56E-4

$\mathrm{C}_{0}, \mathrm{vol} / \mathrm{vol}-\mathrm{psi}$

$4.28 \mathrm{E}-4$

Organic Viscosity:

Temperature, ${ }^{\circ} \mathrm{F}$

Viscosity, $\mathrm{cP}$

100

10.96

140

7.02

4.15

Relative permeability endpoint values:

$S_{\text {wir }}$
$k_{\text {rocw }}$
$S_{\text {orw }}$
$k_{\text {rwro }}$

0.261

1.000

0.280

0.249

Secondary Drainage Capillary Pressure:

$\begin{array}{ll}\frac{S_{w}, \text { frac }}{0.200} & \frac{P_{c w o}, p s i}{0.2170} \\ 0.600 & 0.1662 \\ 0.700 & 0.1482 \\ 0.745 & 0.1349 \\ 0.760 & 0.1138 \\ 0.770 & 0.0161 \\ 0.775 & 0 .\end{array}$


Table A2. Input Data for the Suspended Organic Study (cont.)

Imbibition Capillary Pressure:

\begin{tabular}{lll}
$\frac{S_{w}, \text { frac }}{0}$ & & $P_{\text {cwo }}$, psi \\
\hline 0.200 & & 0.0715 \\
0.600 & & 0.0601 \\
0.650 & & 0.0582 \\
0.720 & & 0.0537 \\
0.750 & & 0.0472 \\
0.760 & 0.0161 \\
0.775 & 0.
\end{tabular}

\section{Water Zone}

Organic saturation, frac. of P.V.

0.00

Water saturation, frac. of P.V.

1.00

Relative permeability endpoint values:

$\begin{array}{cc}\mathrm{S}_{\text {wir }} & 0.2610 \\ \mathrm{k}_{\text {rocw }} & 1.0000 \\ \mathrm{~S}_{\text {Orw }} & 0.0001 \\ \mathrm{k}_{\text {rwro }} & 0.4875\end{array}$

Primary Drainage Capillary Pressure:

$\begin{array}{cc}\frac{S_{w}, \text { frac }}{0.000} & \frac{P_{\text {cwo }}, p s i}{0.2170} \\ 0.600 & 0.1662 \\ 0.700 & 0.1482 \\ 0.745 & 0.1349 \\ * 0.760 & 0.1138 \\ 1.000 & 0.0537\end{array}$

*Point of attachment to capillary pressure curve. 


\section{Aquifer Properties}

Permeability, Darcies

Porosity, fraction

Initial temperature, ${ }^{\circ} \mathrm{F}$

Pressure at grid layer 1 , psi

Injection temperature, ${ }^{\circ} \mathrm{F}$

Injection rate, gm/hr

Production pressure, psia

Aquifer length, $\mathrm{ft}$

Aquifer height, $\mathrm{ft}$

Aquifer thickness, $\mathrm{ft}$
20

0.38

70

11.4

140

511

11.4

3.3

2.0

0.167 


\title{
APPENDIX III
}

\author{
Modifications to WRI's Thermal Model: \\ Development Toward a Field-Scale Simulator
}




\section{MODIFICATIONS TO WRI'S THERMAL MODEL: DEVELOPMENT TOWARD A FIELD-SCALE SIMULATOR}

By

Charles Mones

July 1993

Work Performed Under Cooperative Agreement DE-FC21-86MC11076

For

U.S. Department of Energy Office of Fossil Energy

Morgantown Energy Technology Center

Morgantown, West Virginia

Submitted by

Western Research Institute

Laramie, Wyoming 


\section{TABLE OF CONTENTS}

Page

LIST OF FIGURES $\ldots \ldots \ldots \ldots \ldots \ldots \ldots \ldots \ldots \ldots$

SUMMARY $\ldots \ldots \ldots \ldots \ldots \ldots \ldots \ldots \ldots \ldots$

INTRODUCTION $\ldots \ldots \ldots \ldots \ldots \ldots \ldots \ldots \ldots \ldots \ldots \ldots \ldots$

MODEL MODIFICATIONS $\ldots \ldots \ldots \ldots \ldots \ldots \ldots \ldots \ldots$

Three-Dimensional Formulation $\ldots \ldots \ldots \ldots \ldots \ldots \ldots$

Point-Centered and Variable Grid Spacing .............. 3

Directional Permeability and Interblock Transmissibility . . . . . . . . $\quad 5$

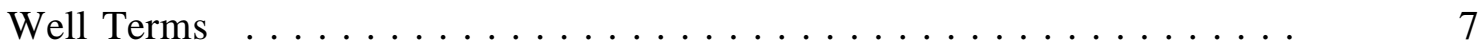

Improvements to Numerical Methods . . . . . . . . . . . . . . . . . . 9

Improvements to Memory Allocation and User Interface $\ldots \ldots \ldots \ldots \ldots$

CONCLUSIONS $\ldots \ldots \ldots \ldots \ldots \ldots \ldots \ldots \ldots \ldots \ldots \ldots \ldots$

ACKNOWLEDGMENT $\ldots \ldots \ldots \ldots \ldots \ldots \ldots \ldots \ldots \ldots$

DISCLAIMER $\ldots \ldots \ldots \ldots \ldots \ldots \ldots \ldots \ldots \ldots \ldots \ldots$

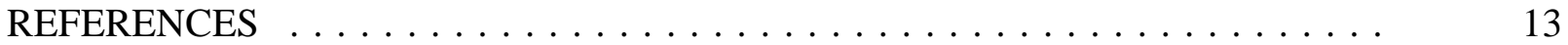




\section{LIST OF FIGURES}

Figure

Page

1. Grid Systems Used by Thermal Simulator . . . . . . . . . . . . 4 


\section{SUMMARY}

This report summarizes work completed under tasks 4.1.7, In Situ Modeling of Pyrolysis Products and 4.3.3, Thermal Reservoir Simulation, of Annual Research Plans under Cooperative Agreement DE-FC21 -86MC 11076. The purpose of this work was to extend Western Research Institute's (wRI's) previously developed numerical simulator that had been used for laboratory studies of thermal processing in porous media to a field-scale reservoir simulator. To accomplish this task, the following modifications were made to the model:

- Ability to describe one-, two-, or three-spatial dimensions

- $\quad$ Configurable for both cell-centered and point-centered grids

- Ability to specify variable grid spacings

- $\quad$ Ability to describe directional perrneabilities

- $\quad$ Ability to modify interlock transmissibilities

- Incorporation of radial well terms in both horizontal and vertical orientations.

In addition, improvements were made to the model numerics to reduce memory storage requirements, improve accuracy, and increase computation speed.

The modifications made to WRI's thermal simulator have greatly enhanced its ability to perform field-scale simulations, particular] y in the areas of three-dimensional reservoir descriptions and depiction of radial well source/sink terms. 


\section{INTRODUCTION}

Western Research Institute (WRI) has previously developed a numerical simulator (TSRS) that describes thermal recovery processes in porous media (Vaughn 1986). The principal application of the model was to support laboratory investigations of combustion steam technologies in tar sand resources. The laboratory simulations consisted of onedimensional tube tests in a $3-\mathrm{ft}$ long reactor and two-dimensional block tests in a $3 \times 3 \times 2-\mathrm{ft}$ sample of reservoir material.

TSRS is a highly implicit, four-phase (oil, water, gas, and coke), multicomponent, finite difference thermal simulator. The model formulation is based on a set ofindividualcomponent mass balance, energy balance, and related constraint equations that account for accumulation, vapor-liquid partitioning, chemical reaction, injection-production, heat conduction, heat loss, and the transport of mass and energy by Darcy flow, Interlock transport of mass and energy are calculated using a single-point upstream fluid mobility and enthalpy in a five-point, block-centered, finite difference scheme on fixed-size Cartesian grids, The components described by TSRS include noncondensable species (oxygen and inert gas), water (liquid and vapor), oil species (light and heavy), and coke. Source-sink terms are accommodated by specification of molar-rate at a grid block or by specification of a source-sink pressure which is used in a one-dimensional, linear flow calculation.

TSRS proved a useful tool for the evaluation of laboratory-scale experiments and the formulation of its equations were sufficient to describe thermal recovery processes (steam flooding, combustion flooding, hot-gas pyrolysis, and hot-water flooding) in petroleum reservoir material. Extending TSRS'S use to field problems required modifications to the model's numerical formulation and the addition of new computational modules that account for physical configurations encountered in full-scale reservoir recovery operations. 


\section{MODEL MODIFICATIONS}

In extending TSRS for use as a field-scale, reservoir simulator, the following modifications were made to the model:

- Ability to describe one-, two-, or three-spatial dimensions

- Addition of point-centered spatial grids

- $\quad$ Ability to specify variable grid spacings

- $\quad$ Ability to describe directional permeabilities

- Ability to modify interlock transmissibilities

- $\quad$ Addition of radial well terms (i.e., source/sink) in both horizontal and vertical orientations

- Improvements to model numerics to reduce memory storage requirements, improve accuracy, and increase computation speed,

These modifications are described below. A detailed description of TSRS'S model equations and numeric techniques are not presented here since they are substantially unchanged in this revised version of the code. Only pertinent descriptions of modification are presented. The interested reader is referred to the detailed description of the model in its original formulation given by Vaughn (1986).

\section{Three.Dimensional Formulation}

The three-dimensional description of a reservoir is essential in performing field-scale simulations. The third spatial dimension was added by increasing the computational gridblock specification to three dimensions in the $\mathrm{x}-, \mathrm{y}$-, and $\mathrm{z}$-directions with respective block counts of NX, NY, and NZ. The discretization equations in three-dimensions form a conventional seven-point computational star with six grids located around the central grid $(i, j, k)$ at locations: $(i-1, j, k),(i+1, j, k),(i, j-1, k),(i, j+1, k),(i, j, k-1)$, and $(i, j, k+l)$ where the indices $\mathrm{i}, \mathrm{j}, \mathrm{k}$ refer to the $\mathrm{x}-, \mathrm{y}-$, and $\mathrm{z}$-directions respectively. The model processes gridblock variables in the order $\mathrm{i}, \mathrm{j}, \mathrm{k}$. As with the original formulation, the model uses singlepoint, upstream weighting in calculating fluid mobility and enthalpy terms, 
The user may specify either a one- or two-dimensional configuration by setting two or one block count variable(s) respectively to the value(s) of one. For ease of use, specification of gravitational force may be in the $\mathrm{x}-$, $\mathrm{y}$-, or z-direction.

\section{Point-Centered and Variable Grid Spacing}

The model was revised to permit the use of either cell-centered or point-centered computational grids. Point-centered grids provide a more accurate representation of performance in pattern studies because wells can be located at grid boundaries. In addition, the point-centered method reduces numerical discretization error in variable grid formulations (Settari and Aziz 1972).

In a cell-centered grid, the computational mesh (the reservoir) is divided into $\mathrm{M}$ number of blocks with the grid point located in the center of each block. The spatial increment, $\Delta \mathrm{x}$, is the distance between adjacent grid points (Figure la). The volume associated with the grid point is defined by the block (or cell) boundaries with the grid point located at the center of the grid blocks.

In the point-centered grid, grids are located at the beginning and end of the computational mesh $(\mathrm{x}=\mathrm{o}$ and $\mathrm{x}=\mathrm{L})$ and distributed at points between. The spatial increment, $\Delta \mathrm{x}$, is the distance between adjacent grid points (Figure lb). In the pointcentered system, cell volumes are determined by constructing boundaries (shown as dashed lines) midway between adjacent grid points. It should be noted that, because grid points are located at the ends of the computational mesh, the point-centered system has one more grid point than the cell centered system (compare Figure la with Figure 1b).

The finite difference operator for both grid systems is identical except in the treatment of boundary conditions. For a no-flow boundary condition $\mathrm{du} / \mathrm{dx}=0$ at both $\mathrm{x}=$ 0 and $x=L$, however, for the cell-centered sy stem, $d u / d x=\left(u_{2}-u_{1}\right) / \Delta x$ at $x=0$ and $d u / d x$ $=\left(\mathrm{u}_{\mathrm{M}-1}-\mathrm{u}_{\mathrm{M}}\right) / \Delta \mathrm{x}$ at $\mathrm{x}=\mathrm{L}$. The model uses the three-point central-difference operator that is $\mathrm{O}\left(\Delta \mathrm{x}^{2}\right)$ accuracy for uniform point spacing. 
Cell Number, $\mathrm{i}$ =

Grid Length, $\mathrm{x}=$

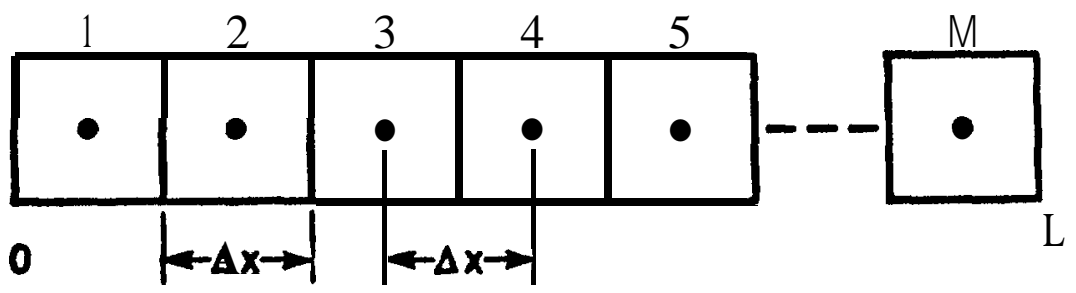

(a) Cell-Centered Grids, Fixed Spacing

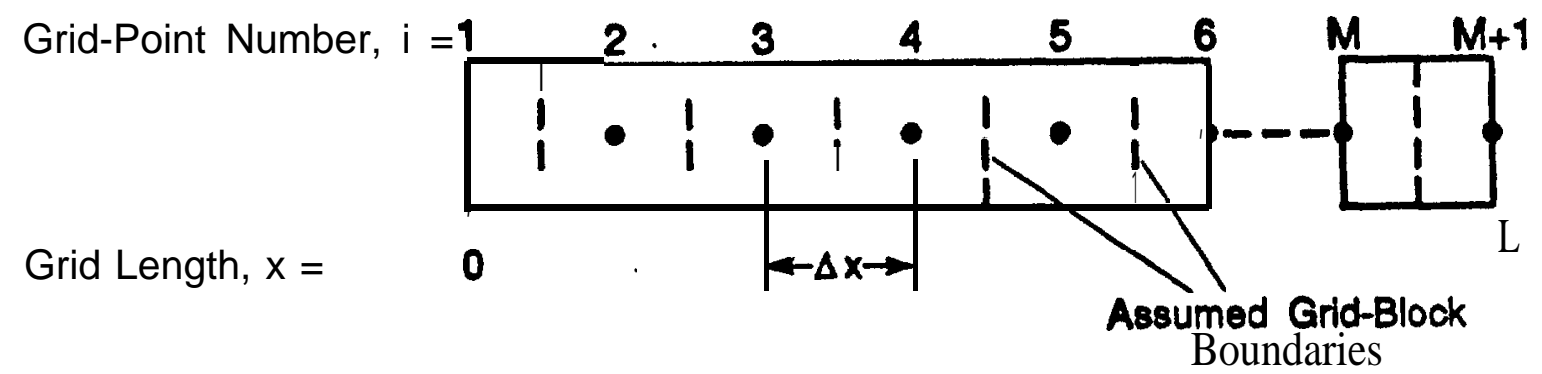

(b) Point-Centered Grids, Fixed Spacing

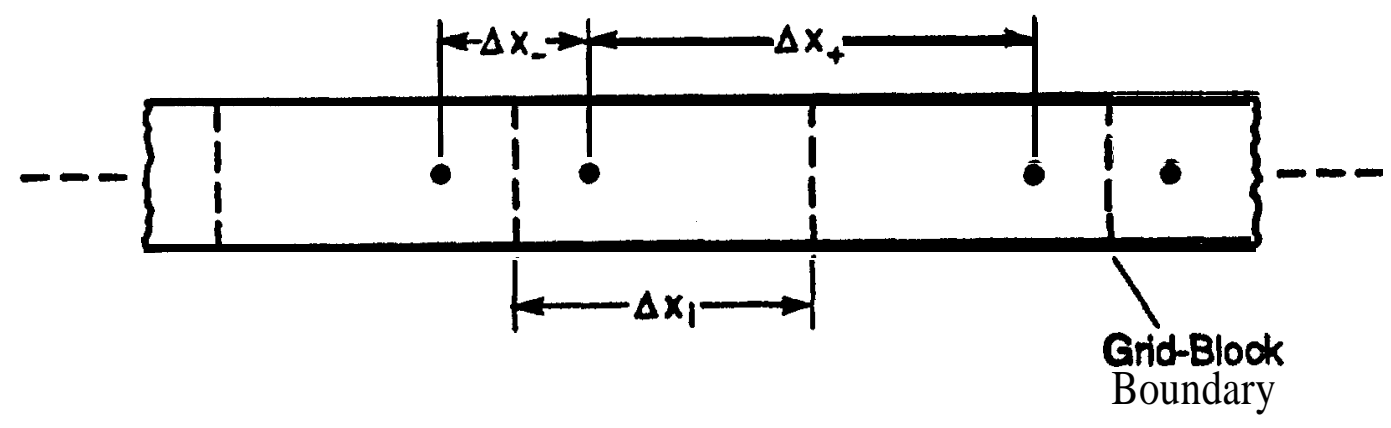

(c) Point-Centered Grids, Arbitrarily Spaoed with Grid-Block Boundary Located Between Adjacent Grid Points

Figure 1. Grid Systems Used by Thermal Simulator 
Variable grid spacing permits the use of closely spaced (refined) grids in regions of large dynamic change within the reservoir and widely spaced grids in regions of small change. This approach provides the numerical accuracy of finely spaced grids while maintaining tractable computation time. The model uses the point-centered gridding scheme for implementation of variable grid spacing because it has been shown that the cell-centered method is of zero order accuracy, $\mathrm{O}\left(\Delta \mathrm{x}^{0}\right)$, (i.e., becomes inconsistent with the difference operator) for arbitrary grid spacings while the point-sentered method maintains a higher (and consistent) accuracy of $\mathrm{O}\left(\Delta \mathrm{x}^{2}\right)$ (Settari and Aziz 1972).

An example of variable grid spacing in the x-direction is shown in Figure 1c, where grid points are arbitrarily distributed with grid boundaries located midway between adjacent grid points. With this configuration the finite-difference representation for convective transport (interblock flow) in terms of $u$ at point $\mathrm{i}$ is given by:

$$
\begin{array}{ll}
L\left(U_{i}\right)= & \frac{2}{\Delta x_{+}+\Delta x_{-}}\left[K_{i+1 / 2} \frac{u_{i+1}-u_{i}}{\Delta x_{+}}+K_{i-1 / 2} \frac{u_{i-1}-u_{i}}{\Delta x_{-}}\right] \\
\text {where } & \Delta x_{+}=x_{i+1}-x_{i} \\
& \Delta x_{-}=x_{i}-x_{i-1}
\end{array}
$$

where $\mathrm{L}$ is the second order difference operator and $\mathrm{K}$ is the average permeability between grids.

\section{Directional Permeability and Interblock Transmissibility}

Directional permeability effects are often exhibited in reservoirs and are typically most pronounced in the vertical direction. Incorporation of directional permeability into the model was done in conjunction with a factoring out of the interblock transmissibility terms from the convective portion of the simulator's mass and energy conservation equations. Segregation of the transmissibility permits the user to specify flow barriers and faults within the simulated reservoir as well as facilitating the history matching process when it becomes necessary to adjust reservoir properties to match production data. A description of the procedure for one-spatial dimension is given below. 
A partial discretization of the convective transport portion of the mass balance equation between grid points $\mathrm{i}-1$ and $\mathrm{i}$ (in the $\mathrm{x}$-direction) may be written as:

$$
\frac{A_{y z}}{\Delta x} \times \frac{1}{\mu_{i-1 / 2}}\left[\left(K_{x}\right)_{i-1 / 2}(k r)_{I 1}\left(P_{i-1}-P_{i}\right)\right]
$$

where $\mathrm{K}$ is rock permeability, $\mu$ is fluid viscosity, $\mathrm{kr}$ is relative permeability, $\mathrm{P}$ is pressure, and $\mathrm{A}_{\mathrm{yz}}$ is cross-sectional area to flow $(\Delta \mathrm{y} \times \Delta \mathrm{z})$. The subscript (i - 1/2) denotes an average permeability between block boundary i-1 and $\mathrm{i}$ and subscript $\mathrm{I} 1$ denotes the relative permeability in the upstream direction (either $\mathrm{i}$ or $\mathrm{i}-1$ ). Subscript $\mathrm{x}$ denotes directional permeability in the $\mathrm{x}$-direction. Upstream weighting is used because it has been shown to most accurately portray, physically, flow in porous media when nonlinear, differential equations are used to describe convective fluid transport. The one-point upstream weighting method is used in the model because it minimizes truncation errors and reduces grid orientation effects in multidimensional problems (Aziz and Settari 1990).

The original model described the balance equations on a grid-block volume basis which was done by dividing by the block volume $\Delta \mathrm{X} \times \Delta \mathrm{Y} \times \Delta \mathrm{Z}$. Expression 2 then becomes:

$$
\frac{1}{\Delta x^{2}} \times \frac{1}{\mu_{i-1 / 2}}\left[\left(K_{X}\right)_{i-1 / 2}(k r)_{I 1}\left(P_{i-1}-P_{i}\right)\right]
$$

The interblock transmissibility between points $i-1$ and $i$ is given by:

$$
\left(T_{x}\right)_{i-1 / 2}=\frac{\left(K_{x}\right)_{i-1 / 2} A_{y z}}{\Delta x}
$$

The transmissibility was factored out of expression 2 giving the following expression on a grid-block volume basis:

$$
\frac{1}{\Delta x \times \Delta y \times \Delta z} \times \frac{1}{\mu_{i-1 / 2}}\left[\left(T_{x}\right)_{i-1 / 2}(k r)_{I 1}\left(P_{i-1}-P_{i}\right)\right]
$$


On input, the user may specify a modification to the $\mathrm{x}-$, $\mathrm{y}-$, or $\mathrm{z}$-direction transmissibilities of the form:

$$
(T)_{\text {modified }}=\left(T_{\text {original }} \times B\right)+C
$$

where $\mathrm{B}$ and $\mathrm{C}$ are modification factors. These factors are used to facilitate performance history matching.

In the current version of the model, a harmonic averaging of the rock permeabilities is used and is of the form:

$$
\left(K_{x}\right)_{i-1 / 2}=\frac{2\left(K_{x}\right)_{i-1}\left(K_{x}\right)_{i}}{\left(K_{X}\right)_{i-1}+\left(K_{x}\right)_{i}}
$$

\section{$\underline{\text { Well Term }}$}

Routines that calculate radial well source and sink terms were added to the model using the technique based on the method developed by Peaceman for nonsquare grid blocks and anisotropic permeability (Peaceman 1983). The implementation in the model permits wells to be oriented in the $\mathrm{x}_{-}, \mathrm{y}-$, or $\mathrm{z}$-direction and be located anywhere within the reservoir. In the following discussion, the axis of the well is presumed to be oriented in the z-direction. Accordingly, the grid spacing and permeabilities used in the example equations are normal to the well direction or in the $\mathrm{x}-\mathrm{y}$ plane. Orientation of the well in another direction requires a simple wmsfonnation of variables to the plane normal to the well direction. The model provides for the appropriate transformation based on a user-specified parameter that is supplied for each well.

Under conditions of pressure control, the source/sink ter-in for a radial well oriented in the $\mathrm{z}$-direction at grid-point $\mathrm{i}$ is determined by:

$$
q_{i}=\frac{2 \pi \Delta z_{i}}{\mu_{i}}\left[\left(K_{x} K_{y}\right)_{i}^{1 / 2}\left(P_{i}-P_{w e l l}\right)\right] \ln \left(\frac{r_{0}}{r_{w}}\right)
$$


and $r_{o}$ is:

$$
r_{0}=0.28 \frac{\left|\left(K_{y} / K_{x}\right)_{i}^{1 / 2} \Delta x_{i}^{2}+\left(K_{x} / K_{y}\right)_{i}^{1 / 2} \Delta y_{i}^{2}\right|^{1 / 2}}{\left(K_{y} / K_{x}\right)_{i}^{1 / 4}+\left(K_{x} / K_{y}\right)_{i}^{1 / 4}}
$$

where $\mathrm{K}_{\mathrm{x}}$ and $\mathrm{K}_{\mathrm{y}}$ are absolute permeabilities in the $\mathrm{x}$ - and $\mathrm{y}$-directions; $\Delta \mathrm{x}, \Delta \mathrm{y}$, and $\Delta \mathrm{z}$ are block dimensions in the $\mathrm{x}-, \mathrm{y}-$, and $\mathrm{z}$-directions; $\mu$ is fluid viscosity, $\mathrm{r}_{\mathrm{w}}$ is the well radius, $\mathrm{P}$ is the grid pressure, and $\mathrm{P}_{\text {well }}$ is the well pressure. In the event that gravitational forces are specified, $\mathrm{P}_{\text {well }}$ incorporates gravity head effects based on the well pressure at a fixed datum. It should also be noted that the above example is for a single flowing fluid. In the case of multiple flowing fluids, one such equation 8 exists for each phase and the relative permeability of the flowing fluid $(\mathrm{kr})$ is included in the numerator, $\mu_{\mathrm{i}}$ becomes the viscosity of flowing fluid phase, and $\mathrm{P}$ becomes the phase pressure.

In addition to sourcing by pressure, the well model has provision for specification of maximum flow rate $\left(\mathrm{q}_{\max }\right)$ and limiting well pressure $\left(\mathrm{P}_{\text {LIMIT }}\right)$. The option automatically partitions flow among constituent layers of the well by using a procedure based on flow rate weighting. The flow for the well is estimated by summing constituent flows from each layer using equation 8 but substituting $\mathrm{P}_{\text {LIMIT }}$ for $\mathrm{P}_{\text {well }}$ :

$$
Q=\sum_{i=1}^{N L A Y E R S} q_{i}
$$

If $\mathrm{Q}$ exceeds or is equal to the maximum specified flow $\left(\mathrm{q}_{\max }\right)$ the well is on flow control and flow is partitioned at layer $\mathrm{i}$ using the algorithm:

$$
q I_{i}=q_{\max } x\left(q_{i} / Q\right)
$$

If $\mathrm{Q}$ does not exceed $\mathrm{q}_{\max }$ the well is on pressure limit control and the source/sink term is as calculated directly by equation 8 with $\mathrm{P}_{\text {LIMIT }}$ substituted for the well pressure. 


\section{Improvements to Numerical Methods}

A refinement was made to the model's numerical solution technique. The refinement improves stability when solving problems that have transitions between high saturation and residual saturation phase components, for example oil floating on water.

The model uses Newton-Raphson iteration (Camahan et al. 1969) for the solution of its set of nonlinear equations. The method requires the construction of a Jacobian matrix that contains partial derivatives formed from the set of equations to be solved. As a typical example, numerical approximations to the partial derivatives are formed by:

$$
\frac{\partial F(a, b)}{\partial a}=\frac{F(a+\Delta a, b)}{\Delta a}
$$

where $\mathrm{F}$ is some arbitrary function in a and b. This approximation is sometimes called a forward method because the incremental change to the function's independent variable, $\Delta \mathrm{a}$, is added to the current value, a, of the function. The modified method, added as an option to the model, is based on the second order operator used to calculate spatial derivatives:

$$
\left.\frac{\partial u}{\partial x}\right|_{I}=\frac{U_{I+1}-U_{r-1}}{2 \Delta x}
$$

where $\mathrm{r}$ designates discrete points in the $\mathrm{x}$-direction and $\mathrm{U}$ is the corresponding functional value.

Applying this technique to the approximation of the partial derivative gives:

$$
\frac{\partial F(a, b)}{\partial a}=\frac{F(a+\Delta a, b)-F(a-\Delta a, b)}{2 \Delta a}
$$

The disadvantage of this method compared to that in equation 12 is that twice as many functional evaluations are necessary to form the elements in the Jacobian matrix. The 
advantage is that the method can significantly increase the model's speed of convergence and enhance stability, For example, a coning study required in excess of 48 hours to complete using derivatives formed by method 12 and 15 minutes using the modified method.

The Newton-Raphson iteration has provided a stable and robust method for the solution of the models' nonlinear equations; however, it is time consuming in terms of function evaluation. To improve execution speed, a modification to the iterative technique has been used as an option, This accelerated technique does not converge quadratically (as does Newton's method) but is usually faster than linearly (Gerald and Wheatley1989). In this method the Jacobian matrix is not recomputed at each iteration step, Rather the same matrix is used for several iteration steps before being recomputed. For a system of $n$ equations the matrix is recomputed every $\mathrm{n}$ iterations. In practice it has been found that the Jacobian matrix must be recomputed significantly more frequently but the accelerated method can reduce execution times by 25 to $50 \%$ depending on the application.

\section{Improvements to Memory Allocation and User Interface}

Although the model's material balance equations are in principle capable of describing any number of gaseous or liquid components, much of the model's internal storage and calculation routines were written to expect two oil components, one water component, one noncondensable gas component, one oil phase, one water phase, and one gas phase. This configuration made the model cumbersome to use when one of the phases did not exist in the reservoir configuration or more phase components were desired. The model has now been revised to permit user specification of the number of phases present and number of components. The revision has been onl y partially successful because the user is still required to make coding changes related to swing component selection and dependant variable selection. However this task is significant] y simplified over the previous version of the model,

The model has been made more efficient by reducing internal memory storage. This has been done in two areas. An internal memory array of size (number of grids x number 
of equation $)^{2}$ has been eliminated by simplifying the routine that calculates the Jacobian matrix of partial derivatives. Source and sink term storage is sized based on the number of wells as opposed to the total number of grids, as was done in the original version of the model.

\section{CONCLUSIONS}

The modifications made to WRI's thermal simulator have greatly enhanced its ability to perform field-scale simulations, particularly in the areas of three-dimensional reservoir descriptions and depiction of radial well source/sink terms, The revised model should be capable of portraying hot-water flooding, steam flooding, and combustion flooding in pattern studies with comparable performance to commercially available reservoir simulators.

However, further improvements are required for the model. A fast iterative solver should be implemented to augment the model's banded, direct-method matrix solver. In addition, a nine-point method should be implemented to more accurately describe steam floods and hot-gas pyrolysis floods. 


\section{ACKNOWLEDGMENT}

The author expresses appreciation to the United States Department of Energy for funding of this work under Cooperative Agreement Number DE-FC21-86MC11076.

\section{DISCLAIMER}

Mention of specific brand names or models of equipment is for information only and does not imply endorsement of any particular brand, 


\section{REFERENCES}

Aziz, K., and A. Settari, 1990, Petroleum Reservoir Simulation. Elsevier Science Publishers LTD, Essex, England, pages 150-155.

Carnahan, B., H.A. Luther, and J.D. Wilkes, 1969, Applied Numerical Methods, John Wiley \& Sons, New York, NY, page 319-329.

Gerald, C. F., and P.O. Wheatley, 1989, Applied Numerical Analysis, Addison-Wesley Publishing Co., Reading, MA, page 146.

Peaceman, D.W., 1983, Interpretation of Well-Block Pressures in Numerical Reservoir Simulation with Nonsquare Grid Blocks and Anisotropic Permeability, Society of Petroleum Engineers Journal, June 1983,531-543.

Settari, A., and K. Aziz, 1972, Use of Irregular Grid in Reservoir Simulation, Society of Petroleum Engineers Journal, April 1972, page 103-114.

Vaughn, P., 1986, A Numerical Model for Thermal Recovery Processes in Tar Sand: Description and Application, DOE report. 